\title{
Residual Saturation:
}

\section{What is it? How is it measured? How should we use it?}

\author{
Mark Adamski1, Victor Kremesec ${ }^{2}$, Randall J. Charbeneau ${ }^{3}$ \\ ${ }^{1}$ Group Environmental Management ${ }^{4}$, Inc., 501 Westlake Park Blvd., Houston, TX 77079 \\ ${ }^{2}$ Group Environmental Management ${ }^{4}$, Inc., 150 West Warrenville Road, Naperville, IL 60563 \\ ${ }^{3}$ Department of Civil Engineering, The University of Texas, Austin, TX 78712 \\ ${ }^{4}$ A BP Affiliated Company
}

\begin{abstract}
A review of methods to estimate residual NAPL saturation values has been conducted. Traditional laboratory methods use high capillary pressures in saturating the porous media with NAPL to an artificially high starting point. This often results in over-estimation of residual NAPL saturation, especially for environmental applications in surficial shallow aquifers. Comparison of literature values with 270 LNAPL measurements from 10 field sites confirms that many of the literature residual NAPL saturation values are not consistent with field observations. It is concluded that laboratory methods for estimation of residual NAPL saturation values should be developed to include water saturation and capillary pressures that are representative of NAPL releases to shallow subsurface environments.
\end{abstract}




\section{Introduction}

The general concept of residual non-aqueous phase liquid (NAPL) saturation should be straightforward; it is basically the NAPL that cannot be mobilized and recovered from a soil. However, there are many different definitions in different organizations and many different methods of determining residual NAPL saturation. These differences have led to a wide range in literature and perceived values for residual NAPL saturation. The definition of, method for determining, and the value of residual saturation depends on the application.

The objective of this paper is to consider how the generally accepted concepts of residual saturation apply to shallow (i.e. near water table) environmental NAPL remediation projects. It is our belief that the standard or generally accepted concepts and measurement techniques need to be applied differently for the typical unconfined aquifer situations that are normally encountered in the recovery of LNAPL. This paper will include a review of the definitions, the methods historically used to determine the values, and literature values for residual NAPL saturation. It will also present recent field measurement of LNAPL saturations at field sites. Based on observed LNAPL saturation field data, the need to re-evaluate the literature values is evident. As such, a discussion pertaining to the applicability of literature residual saturations to shallow NAPL remediation projects and suggestions for new methods to determine residual saturation are provided.

Before a realistic definition of residual saturation can be developed, the concept of residual saturation must be discussed to clarify important issues. Historically, most investigations of multiphase fluid flow in porous media were conducted by the petroleum industry. For strong economic reasons the petroleum industry has interest in determining the volume of oil that would be trapped and not recoverable from oil reservoirs. As a result of this interest, the largest volume of published data on residual NAPL (oil) saturations was produced by the oil industry.

Soil scientists and agronomists have historically been interested in soils ability to conduct and retain water. The water retention characteristics of a soil are specified by its characteristic or retention curve, which relates the water content to the soil matric suction pressure (capillary pressure between the soil, air, and water). With a supply of water readily available from heavy rainfall or infiltration, the soil pores become filled with water and the maximum retention capacity of the soil is reached, with the matric suction essentially zero. If the water supply is then cut off, water will drain from the soil under the force of gravity, with the larger pores (macropores) draining first. Following a period of rapid drainage (a day or so), the drainage rate becomes negligible. Water is still retained in the smaller (capillary) pores and the capillary pressure is in the range 0.1 to $0.5 \mathrm{~atm}$ (Richards, 1950), and the soil is at field capacity. Growing plants will continue to absorb water from the soil until the capillary pressure reaches a value of about $15 \mathrm{~atm}$, and the soil is at wilting point (Brady, 1974). The irreducible water content corresponds to a limit of infinite suction pressure (Brooks and Corey, 1964). Of these characteristics, field capacity is of most interest for the manuscript. It corresponds to the water (wetting phase) that is held in the soil by capillary forces against the force of gravity. In hydrology, this is the specific retention (Bear, 1972). The drainable porosity is the specific yield, and the sum of the specific yield and specific retention is the maximum retention capacity (porosity) of the soil. Operationally, field capacity or specific retention may be defined as the water content corresponding to a capillary pressure of 1/3 atm (Brady, 1974; Hillel, 1982).

More recently, environmental remediation professionals have become interested in these concepts and how they pertain to recovery of NAPL contaminants from porous media. With regard to residual NAPL saturation, both the petroleum and environmental disciplines are concerned with the movement of liquid in the liquid phase, as opposed to vapor migration in the gas phase. Corey (1986) states "it is clearly possible to remove practically all of the wetting fluid from a porous sample by evaporation." Thus, all the definitions of residual NAPL saturation are based on liquid movement by gravitational and hydraulic forces. 


\section{Background}

\section{Definitions of Residual NAPL Saturation}

\section{Field Scale Definitions of Residual NAPL Saturation}

Field scale definitions define residual NAPL saturation in terms of NAPL mobility relative to the scale of the problem (e.g. oil reservoir production, NAPL plume recovery). One definition for residual oil saturation is focused on liquid saturated conditions in the reservoir or aquifer when oil (or LNAPL) ceases to be recovered. For example, the Petroleum Engineering Handbook (Bradley et al., 1987) defines residual oil as "the liquid that remains in an oil reservoir at depletion". The value of residual saturation from these definitions is dependent upon the vertical and horizontal sweep efficiency, the heterogeneity of the geologic system, and the microscopic displacement efficiency. Microscopic displacement efficiency is primarily dependent upon capillary forces (as will be explained below) but are also dependent upon viscous and gravitational forces (expressed in the capillary and bond number (respectively) and help to explain the microscopic detail of capillary trapping in multiphase flow problems when large pressures or changes in interfacial properties are used. The reader is referred to Bedient et al. (1994) and Wilson et al. (1990) for more information on role of capillary and bond numbers.

Morrow (1987) defines residual oil saturation as the "oil that remains in the swept zone of a waterflood when the produced ratio of water to oil has reached its economic limit." Some environmental researchers have chosen to use similar pragmatic yet vague definitions for residual saturation of "the saturation (vol. of NAPL / vol. of voids) at which the NAPL becomes discontinuous and is immobilized by capillary forces under ambient groundwater flow conditions" (Mercer and Cohen, 1990). Schwille (1984) and Domenico and Schwartz (1990) have defined residual NAPL saturation similarly. These definitions seem to be most concerned with areas of the field where vertical and areal sweep efficiencies are near unity and water has been forced or allowed to sweep the LNAPL from the pores. These may be the best-defined values of residual, but measurement is extremely difficult and/or costly. It is virtually impossible to know the value a priori. For this reason, laboratory measurements have been attempted.

\section{Laboratory Definitions of Residual NAPL Saturation in Unsaturated conditions}

The soil science and environmental disciplines have been more concerned with near surface conditions and have needed to consider residual NAPL saturation in both the vadose (unsaturated soil above saturated soil) and saturated zones. Focusing primarily on the vadose zone, Hoag and Marley (1986) define residual saturation as the saturation that is attained after an initially saturated porous media is allowed to drain by gravity to equilibrium conditions. Zytner et al., (1993) use a similar definition for residual saturation but do not explicitly state an initially NAPL saturated condition in the porous media. These definitions are analogous to field capacity for the wetting phase. In addition to residual saturation, Schwille (1984, 1988), Mercer and Cohen (1990) and Zytner et al., (1993) define the term retention capacity to describe residual saturation of the non-wetting phase in the vadose zone in terms of NAPL per unit volume of soil. The retention capacity $(\mathrm{RC})$ is defined as:

$$
\mathrm{RC}=\mathrm{S}_{\text {or }} \times ? \times 1000
$$

In equation $(1), \mathrm{RC}=$ retention capacity (liters of NAPL $/ \mathrm{m}^{3}$ of soil), $\mathrm{S}_{\mathrm{or}}=$ residual saturation (volume of NAPL / vol. of voids), and ? = soil porosity (-).

\section{Laboratory Definitions of Residual NAPL Saturation in Saturated Conditions}

This paper is most concerned about the value used for "residual" NAPL saturation in saturated conditions. This is because many environmental remediation projects are conducted with the goal of recovering nonaqueous phase liquids (NAPL). State and Federal regulations require that NAPL be recovered to some endpoint state, generally either, recovery of all NAPL; some minimal thickness remaining (e.g. $1 / 8^{\text {th }}$ inch); or technical impracticability of continued recovery. To estimate the potential recovery and the volume of LNAPL left in-place, models require an estimate of the amount of NAPL that will remain in the porous media. As a result of the role of residual NAPL saturation in defining the immobile fraction of the total NAPL in-place, residual NAPL saturation is a critical parameter. 
Perhaps the most common definition of residual saturation in saturated conditions is the value that would be obtained in the laboratory imbibition of water into a NAPL saturated soil core. In laboratory core tests the porous media is initially saturated with the wetting fluid (water). Capillary pressure (pressure of the non-wetting fluid - NAPL) is then progressively increased until the expulsion of the wetting fluid from the sample has become negligible (see the primary drainage curve shown in Figure 1); this point is often referred to as the irreducible water saturation. The pressure of the non-wetting fluid is then slowly decreased until the pressure of the wetting and non-wetting fluids are equal, capillary pressure is zerocorresponding to saturated or water table conditions (see the spontaneous imbibition curve in Figure 1). Relative to the saturated zone, many researchers, Pickell et al. (1966), Bear (1972), Dullien (1979), Fetter (1992), Freeze and McWhorter (1997) have defined residual saturation based on drainage and imbibition experiments defining residual saturation as the non-wetting phase saturation at zero capillary pressure at the terminus of the spontaneous imbibition curve.

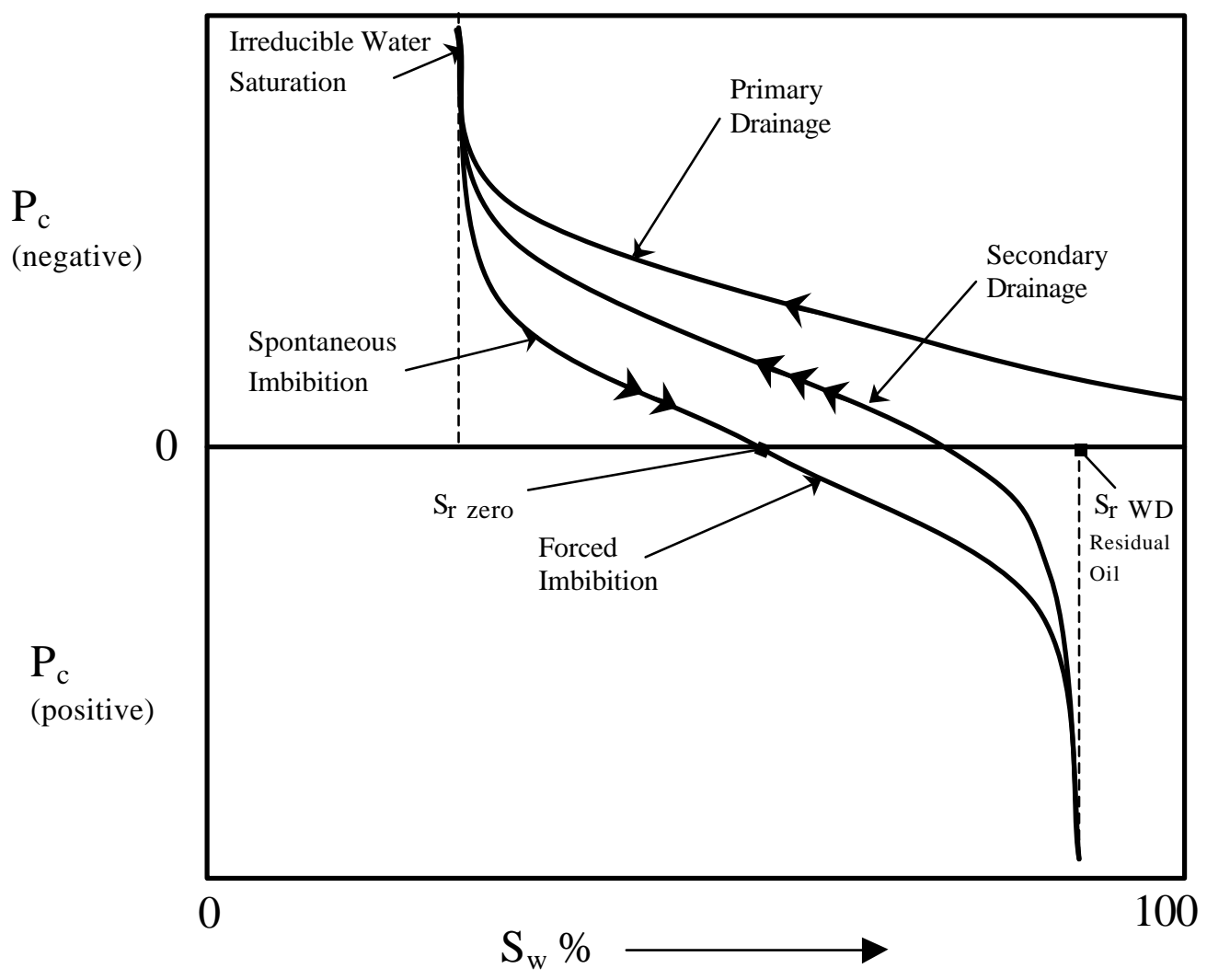

Figure 1: Example drainage and imbibition curves including forced imbibition and secondary drainage. $\mathrm{S}_{\mathrm{r} \text { zero }}$ is the oil NAPL where the imbibition curve reaches capillary pressure of zero. $\mathrm{S}_{\mathrm{r}}$ WD is the NAPL saturation where NAPL recovery ceases after forced imb ibition. (After Morrow 1990)

Summarizing the soil science and environmental definitions for residual NAPL saturations there tend to be two subset definitions: 1) residual NAPL saturation in the vadose zone generally defined in a fashion analogous to field capacity, the NAPL saturation which remains in the soil after gravity drainage has become negligible, and 2) residual NAPL saturation in the saturated zone. There are two approaches for defining residual NAPL saturation in the saturated zone: A) the NAPL saturation which remains in the soil after water has imbibed to a capillary pressure of zero (per drainage / imbibition laboratory tests), and B) the NAPL saturation at which the NAPL has become immobilized by capillary forces while subject to groundwater flow conditions. The difference in these two definitions is that definition A describes a return to zero capillary pressure whereas definition B implies the possibility of slight additional water imbibition 
(lower NAPL saturations) resulting from the forced imbibition induced by water flow associated with a groundwater gradient. In many soils, the difference between A and B is very small.

\title{
Methods of Determining Residual NAPL Saturation
}

\author{
Methods of Determining Residual NAPL Saturation (Field Scale)
}

It is generally accepted in the petroleum industry that residual oil saturations in the reservoir can range from $15 \%$ to $50 \%$ (Wilson et al., 1990). To better understand and measure residual oil saturation the petroleum industry has developed tracer test methods to determine residual oil saturation in-situ. These methods evaluate the residual saturation in the vicinity of a borehole. In a study involving 92 determinations of residual oil content in reservoirs the residual oil saturation was found to range from $2 \%$ to $46 \%$ with an approximate average of $15 \%$ to $20 \%$ Morrow (1987). For comparison, in a laboratory (coreflood) test of 424 core samples the residual oil saturation was found to range from $5 \%$ to $60 \%$ with an approximate average of $25 \%$ - 35\%, leading Morrow (1987) to conclude that laboratory coreflood determinations result in higher residual oil saturations than do in-situ measurements.

Some environmental DNAPL researchers have attempted to measure residual NAPL saturation in-situ. Poulsen and Kueper (1992) spilled dyed tetrachloroethylene (PCE) into a sand field site. After the PCE was allowed to percolate through the soils the site was carefully excavated in 10 to $15 \mathrm{~cm}$ lifts to allow for detailed mapping and small-scale $(2 \mathrm{~mL})$ soil sampling. The results of the small-scale sampling and analysis revealed that the residual DNAPL saturation in the sand ranged from 0.2 to $18 \%$ (0.002 to 0.18$)$ and were dependent on slight variations in soil permeability. Poulsen and Kueper (1992) found the largescale average residual DNAPL saturation to range from 1 to $2.5 \%$ for drip and instantaneous spill scenarios respectively.

More recently other researchers have modified the oil industry method of tracer testing to determine residual DNAPL saturation in-situ surrounding observation wells. Jin et al. (1997) and Young et al. (1999) have used the technique of partitioning inter-well tracer testing (PITT) to determine residual DNAPL (and LNAPL) saturations both prior to and following surfactant enhanced waterflood NAPL recovery efforts. Young et al. (1999) report DNAPL saturations ranging from $0.1 \%$ to $0.2 \%$ saturation prior to surfactant flooding and $0.06 \%$ residual DNAPL saturation upon completion of the surfactant flood. Jin et al. (1997) cite three case studies where PITT determined the residual DNAPL saturations to range from 0.02 to 0.10 (2 to $10 \%$ ).

These field methods are a very pragmatic and direct approach to determine the residual oil saturation. These determinations of residual oil saturation are very useful yet difficult and costly to conduct. This being the case, these methods are not the most useful for modeling or initial assessment of LNAPL recoverability.

\section{Laboratory Methods in Petroleum Applications}

The petroleum industry has long been interested in the volume of oil that remains in the reservoir after oil production has ceased. Thus the experiments conducted by the petroleum industry have been designed to mimic reservoir conditions. A typical industry laboratory method for determining residual oil saturation in core analysis, API (1998) specifies a rock core be completely saturated with the non-wetting phase (oil displacing water) often by applying oil pressures in the range of 500 to $1000 \mathrm{psi}$ (approx. 2,300 $\mathrm{ft}$ of water), refer to Figure 1. This oil saturation and capillary pressure then defines the maximum oil saturation and starting point for the imbibition test, and is analogous to the irreducible saturation of the wetting phase. Water is then imbibed into the same core until oil expulsion has ceased; again, this is commonly accomplished with very high water pressures (500 to $1000 \mathrm{psi}$ ). The resulting oil saturation is the residual oil saturation that can be interpreted to result from a water flood of the reservoir.

As described earlier, laboratory coreflood methods produce higher estimates for residual saturation than insitu tracer test determinations of residual saturation because the laboratory methods force large initial 
NAPL saturation throughout the entire pore space of the sample and displace water from progressively smaller pores (Morrow, 1987 and Pickell et al., 1966). During laboratory core analyses, such as those described above, a very good correlation has been documented between capillary pressure (excess pressure of the non-wetting fluid), the initial saturation of the non-wetting fluid, and the residual saturation, as shown in Figure 2 (Pickell et al., 1966; Wardlaw and Taylor, 1976; and Chatzis and Dullien, 1981). These researchers observed that as porous media is exposed to progressively higher non-wetting phase pressures the maximum (initial) saturation of the non-wetting phase also increased, as is depicted by points (1), (2), and (3) in Figure 2. As the maximum saturation of the non-wetting phase increased, the residual saturation was also found to increase, points $S_{\mathrm{r}(1)}$ through $S_{\mathrm{r}(3)}$ in Figure 2. Thus, the residual saturation of a porous medium is a function of the non-wetting phase pressure history (Pickell et al., 1966 and Morrow, 1987).

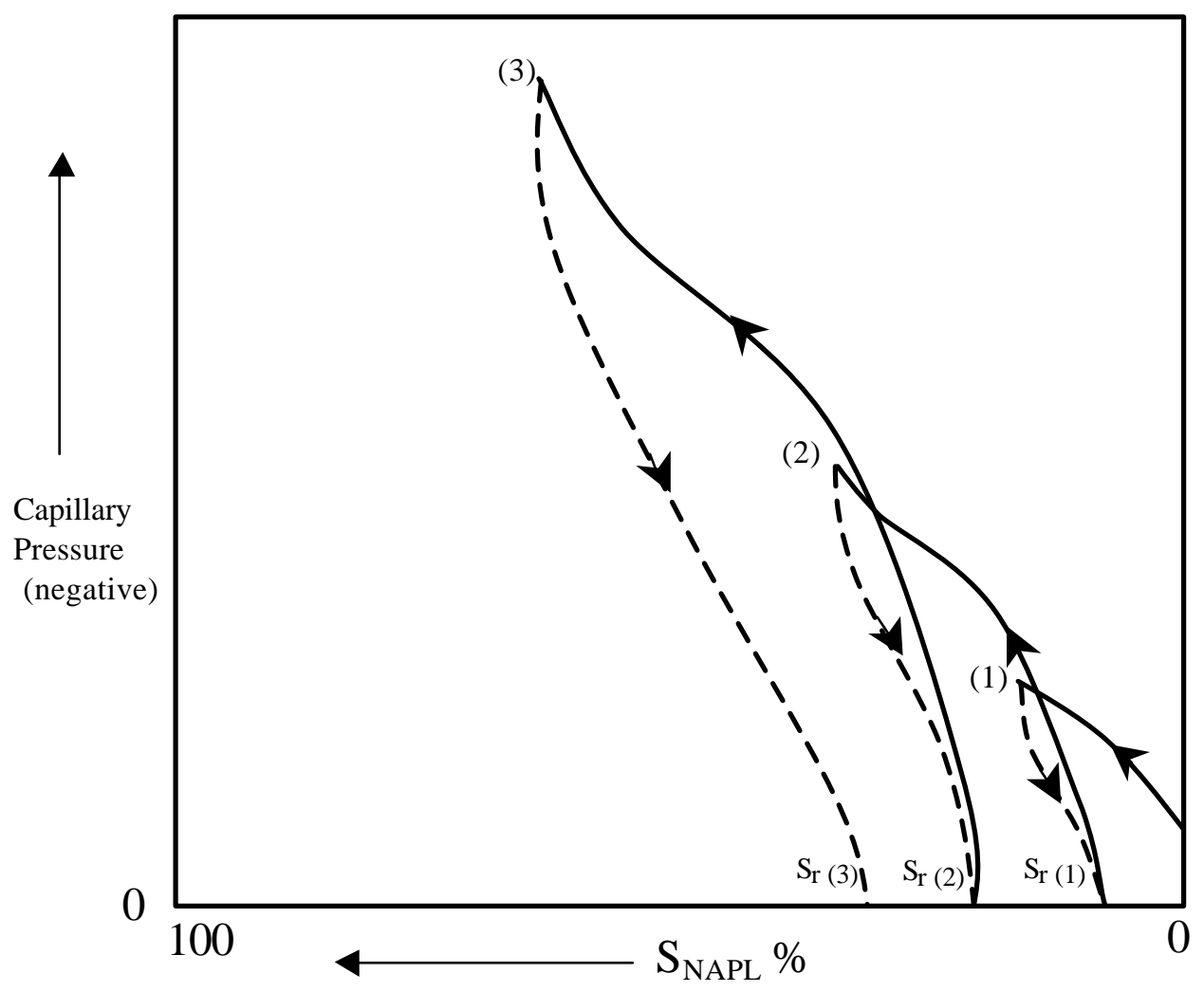

Figure 2: Schematic depicting three hysteresis loops with progressively higher non-wetting phase maximum pressures (1), (2), and (3) and the corresponding residual saturations $\mathbf{S}_{\mathrm{r}}$. (After Pickell et al. 1966)

\section{Methods in Environmental Applications}

Mercer and Cohen (1990) summarized the environmental residual saturation data that was published prior to 1990. Wilson et al. (1990) conducted several tests on three sands and one loam soil. Brost and DeVaull (2000) updated the Mercer and Cohen (1990) summary of available literature residual saturation values by including more recent work by Poulsen and Kueper (1992), Zytner et al. (1993) and Boley and Overcamp (1998). These papers present a majority of the literature values that are available for residual NAPL saturation relative to environmental applications. From their review of the data Mercer and Cohen (1990) summarized " $S_{\mathrm{r}}$ (residual saturation) values typically range from 0.10 to $0.20(10-20 \%)$ in the vadose zone."... "values of $S_{\mathrm{r}}$ in saturated media generally range from 0.15 to 0.50 (15-50\%)." Zytner et al. (1993) restated this same range of values for residual saturation in both the vadose and saturated zones. Wilson et al. (1990) observed residual saturations in saturated unconsolidated sands to range from 0.14 to $0.30(14 \%$ to $30 \%)$ and a lower value, $0.09(9 \%)$, for one unsaturated (vadose zone) sand. In the one loam 


\begin{tabular}{|c|c|c|c|c|}
\hline \multicolumn{5}{|c|}{$\begin{array}{l}\text { Table } 1 \\
\text { ry Residual Saturation Analyses }\end{array}$} \\
\hline Reference & Test Method & Liquid & $\begin{array}{l}\text { NAPL } \\
\text { method of } \\
\text { Introduction }\end{array}$ & Results \\
\hline $\begin{array}{l}\text { Boley \& } \\
\text { Overcamp, } \\
1998\end{array}$ & $\begin{array}{l}\text { Column with } \\
\text { moist glass } \\
\text { beads and sand; } \\
\text { water flushing } \\
\text { after NAPL }\end{array}$ & O-xylene & $\begin{array}{l}\text { Small (5ml) } \\
\text { spill from top }\end{array}$ & $\begin{array}{ll}\text { Med. Sand: } & \text { No Flushing } \mathrm{S}_{\mathrm{r}}=4 \%(0.04) \\
& 30 \text { flushes } \mathrm{S}_{\mathrm{r}}=2 \%(0.02) \\
\text { Coarse Sand: } & \text { No Flushing } \mathrm{S}_{\mathrm{r}}=3 \%(0.03) \\
& 30 \text { Flushes } \mathrm{S}_{\mathrm{r}}=1 \%(0.01)\end{array}$ \\
\hline $\begin{array}{l}\text { Hoag \& } \\
\text { Marley, } \\
1986\end{array}$ & $\begin{array}{l}\text { Column with } \\
\text { dry and field } \\
\text { capacity (FC) } \\
\text { washed fine, } \\
\text { medium, } \\
\text { coarse, and } \\
\text { mixed sand }\end{array}$ & Gasoline & $\begin{array}{l}\text { Gasoline } \\
\text { saturated from } \\
\text { bottom of } \\
\text { column }\end{array}$ & $\begin{array}{l}\text { Dry fine to coarse sand } S_{\mathrm{r}} \text { range } 55 \text { to } 14 \% \\
\text { respectively } \\
\text { Field Capacity fine to medium sand } S_{\mathrm{r}} \text { range } \\
26 \text { to } 12 \% \text { respectively }\end{array}$ \\
\hline $\begin{array}{l}\text { Schwille, } \\
1988\end{array}$ & $\begin{array}{l}\text { Column with } \\
\text { three sands }(\mathrm{K}= \\
10^{-2}, 10^{-3}, 10^{-4} \\
\mathrm{~cm} / \mathrm{sec}) \text { dry and } \\
\text { at field capacity }\end{array}$ & $\begin{array}{l}\text { Chlorinated } \\
\text { Hydrocarbons }\end{array}$ & $\begin{array}{l}\text { Injected at top } \\
\text { until } \\
\text { "uniformly and } \\
\text { completely } \\
\text { impregnated" }\end{array}$ & $\begin{array}{ll}\text { Saturated zone: } & \begin{array}{l}\mathrm{S}_{\mathrm{r}} \text { ranges } 2-15 \%,(0.02- \\
0.15) \text { High to Low } \mathrm{K}\end{array} \\
& \\
\text { Unsaturated zone: } \mathrm{S}_{\mathrm{r}} \text { ranges } 1-10 \%,(0.01- \\
0.10) \text { High to Low K }\end{array}$ \\
\hline $\begin{array}{l}\text { Wilson et } \\
\text { al., } 1990\end{array}$ & $\begin{array}{l}\text { Columns with } \\
\text { three sands and } \\
\text { one loam, field } \\
\text { capacity and } \\
\text { water saturated }\end{array}$ & Soltrol & $\begin{array}{l}\text { Injected under } \\
\text { pressure to } \\
\text { irreducible } \\
\text { water } \\
\text { saturation (not } \\
\text { attained in } \\
\text { loam sample) }\end{array}$ & $\begin{array}{l}\text { Vadose Zone: Sevilleta Sand } \mathrm{S}_{\mathrm{r}}=9.1 \% \\
\qquad(0.091) \\
\text { Palouse Loam }- \text { not completed } \\
- \text { could not reach } \mathrm{S}_{\mathrm{wir}} \\
\text { Saturated Zone: Three sands } \mathrm{S}_{\mathrm{r}}=14-30 \% \\
(0.14-0.30) \\
\text { Palouse Loam }- \text { not completed } \\
- \text { could not reach } \mathrm{S}_{\mathrm{wir}}\end{array}$ \\
\hline $\begin{array}{l}\text { Zytner et al., } \\
1993\end{array}$ & $\begin{array}{l}\text { Column with } \\
\text { sieved and air } \\
\text { dried, sand, } \\
\text { clay, mix, and } \\
\text { peat }\end{array}$ & $\begin{array}{l}\text { PCE, TCE, \& } \\
\text { Gasoline }\end{array}$ & $\begin{array}{l}\text { Saturated from } \\
\text { top with } \\
\text { hydrocarbon } \\
\text { then allowed to } \\
\text { gravity drain } \\
\end{array}$ & $\begin{array}{r}\text { Gasoline in Sandy Loam: } \mathrm{S}_{\mathrm{S}}=42 \%-59 \% \\
(0.42-0.59) \\
\text { Gasoline in Clay: } \mathrm{S}_{\mathrm{r}}=68 \%-75 \%(0.68-0.75) \\
\text { TCE in Sandy Loam: } \mathrm{S}_{\mathrm{P}}=75 \%-92 \% \\
(0.75-0.92)\end{array}$ \\
\hline
\end{tabular}

soil tested Wilson et al. (1990) could not drain the soil using the laboratory pressures that were available and could not reach the irreducible water saturation (fully saturated NAPL initial condition) and thus felt they could not report a residual saturation. To understand the applicability of these values to the typical shallow environmental NAPL problem we must understand the methodology used to develop the values.

Table 1 is a summary of the more recent publications determining residual NAPL saturation through laboratory experiments as it pertains to environmental NAPL recovery problems. It can be seen in Table 1 that a wide range in methodologies has been used to determine residual NAPL saturations in soils. For efficiency purposes, most the analyses have been conducted on well-sorted sands. Most have tested the effects of initial water content on residual NAPL saturation. All, excluding Wilson et al. (1990), were conducted with soil in repacked columns under gravity drainage conditions. Wilson et al. (1990) used repacked, pressurized columns to develop excess wetting and non-wetting phase pressures. All are in general agreement that as the soils initial water content increases the residual NAPL saturation for that soil decreases (Hoag and Marley, 1986; Zytner et al., 1993). It was also concluded that residual saturation increases with decreasing grain-size or permeability (Schwille 1988; Hoag and Marley, 1986; Wilson et al., 1990; Zytner et al., 1993; Boley and Overcamp, 1998). 


\section{Observed Field Conditions - LNAPL Saturations from Ten Field Sites}

During assessment activities for 10 sites, including 7 refineries, 2 chemical plants and 1 fuel storage terminal, saturation analyses were conducted to determine the LNAPL saturation and distribution in the soil profile. The soil samples collected for these analyses were obtained from the most severely LNAPL impacted areas within the facilities, some with LNAPL thickness observed in observation wells that exceeded $15 \mathrm{ft}$. In total, 270 distillation extraction (Dean Stark) LNAPL saturation analyses (API, 1998) were performed. The Dean Stark method of oil saturation determination involves distillation of water and solvent extraction of oil from the porous media. Analysis of this saturation data produced the following statistics: Maximum LNAPL saturation in any sample was $56 \%$ while the average LNAPL saturation was $5.3 \%$. $49 \%$ of the soil samples contained less than $2 \%$ LNAPL saturation while $83 \%$ of the samples contained less than $10 \%$ LNAPL saturation. Some may feel that the observed saturations above are low due to LNAPL draining from the samplers during sample handling. Due to the heterogeneous nature of the soils in the samples, the low relative LNAPL permeability at low LNAPL saturations, often high LNAPL viscosities, and iced or frozen nature of the majority of the cores the authors do not believe LNAPL drainage from the samples prior to analysis is a significant concern.

The LNAPL saturation data collected from, for example, one typic al fine-grained soil (FGS) site provides interesting data. Similar observations have been made at other sites with a full range of soil types. The site is a former refinery situated in the Midwestern United States and the impacted soils at the site that were analyzed consist of lean clay with sand (CL). Two borings, located in the immediate vicinity of observation wells that contain 11 to 16 feet of LNAPL, were continuously sampled and 26 soil samples were collected for laboratory LNAPL saturation analysis from the soil horizons that were visibly impacted with LNAPL. The results of the 26 LNAPL saturation analyses found the maximum LNAPL saturation within the FGS at the site to be $7.6 \%$ with an average value of 2.3\% LNAPL saturation. The boring which contained the $7.6 \%$ maximum LNAPL saturation was within 20 feet of an observation well that contained an LNAPL thickness of 11.8 feet of mixed light and middle distillate (gasoline and diesel). The second boring, that was sampled for LNAPL saturation analysis, was located within 10 feet of an observation well that contained $16 \mathrm{ft}$ of LNAPL (weathered diesel). In this second soil boring the maximum measured LNAPL saturation, of the 11 analyses that were performed, was $1.4 \%(0.014)$.

\section{Discussion}

The data discussed above from the FGS site created difficulty in trying to assess LNAPL distribution and recoverability. When compared to all the literature values discussed previously it was evident that the maximum LNAPL saturation of $1.4 \%$ near the well containing $16 \mathrm{ft}$ of diesel was far below the literature residual NAPL saturation values for any porous media, especially a fine grained soil. By the fact that there is $16 \mathrm{ft}$ of diesel in the observation well there must be LNAPL that exceeds the residual saturation of the soil surrounding this observation well.

Most of the cited references in Mercer and Cohen (1990) and in Table 1 use soils that consisted of wellsorted sand. Only Zytner et al. (1993) included clayey soil in the determination of residual LNAPL saturation, but they applied gasoline to air dried, repacked clay in the column test where gasoline would act as the wetting fluid and be drawn into the pores by capillary forces. Water saturations in the vadose zone at the FGS site have been measured and are $90 \%$ within 4 feet of the ground surface ( 4 feet above the water table). Thus the soil is water saturated and the LNAPL must develop hydraulic pressure in excess of the water pressure to displace the water from the water-wet pores. Adamski et al. (2003) discuss the conceptual model of LNAPL migration in these fine-grained soils, including the LNAPL distribution, model predicted LNAPL recovery, and actually LNAPL recovery from this site. Charbeneau (2003) also uses data from this site as an example of how to model LNAPL recovery in FGS.

Based on the findings of previous work described above, the initial (maximum) NAPL saturation in a soil is a function of the NAPL pressure history and the resulting residual NAPL saturation has been shown to be a function of the initial NAPL saturation. The majority of the literature residual NAPL saturations started from an initial NAPL saturation that corresponds to the irreducible water saturation that is only achieved in typical soils by applying large NAPL (capillary) pressure. This starting point is sensible for petroleum 
applications where the NAPL does develop high pressures. However, shallow environmental problems do not generate large excess (relative to water) NAPL pressures. In the environmental problems the NAPL develops the excess pressure only from ponding of the spill and potentially from hydrostatic column during infiltration and percolation in the vadose zone. This hydrostatic excess pressure would only develop when the NAPL is confined to some macropore network in the vadose zone and would likely not exceed 0.3 to 4 psi (1 to $10 \mathrm{ft}$ of LNAPL head).

The values determined for residual DNAPL saturation in-situ by Poulsen and Kueper (1992) and Young et al. (1999) would possibly provide sensible guides to estimate the residual NAPL saturation for the FGS site discussed above. It appears that field techniques for determination for residual NAPL saturation may provide values that are more applicable to field application while the currently available laboratory determined literature values do not. This is not because it is impossible to determine applicable residual NAPL saturation in the laboratory, but rather because the laboratory methods previously used did not closely simulate the field conditions.

\section{Conclusions - Recommendations for Determining Residual Saturation}

Based on the pressures used during the petroleum industry standard tests it is evident that those laboratory techniques should not be used to determine residual NAPL saturations for environmental problems. As a result of the wide variation of methodology and test procedures such as, dry soils, repacked columns containing mostly well sorted sands, and fully saturated initial NAPL conditions used by environmental researchers it is evident that these literature values are not applicable to most environmental NAPL field sites. Relative to residual saturation, Kueper et al. (1993) conclude that:

"... It also follows that caution should be exercised when measuring a residual content in the laboratory and applying it to a field situation. Unless the laboratory derived value was obtained under identical flow conditions as the field (same initial non-wetting saturation), it should not be used for field-scale calculations of retention capacity."

Based on the work of Pickell et al. 1966, Wardlaw and Taylor 1976, and Chatzis and Dullien 1981, it is evident that the residual NAPL saturation for a porous medium is dependant upon both the soil pore size distribution and the initial NAPL saturation. Based on first principles and the work of Hoag and Marley (1986) and Zytner et al. (1993), it is evident that the initial NAPL saturation and thus the residual NAPL saturation is dependant upon the soil water saturation at the time of the NAPL release. Since laboratory derived environmental residual NAPL saturation data discussed above are based on reworked, predominantly well sorted sands at varying initial moisture contents, it is unlikely that those values would be applicable at environmental NAPL sites that are not located in well sorted sand.

In efforts to model NAPL recoverability, the authors have found it most effective to estimate residual NAPL saturation as some subset of the maximum observed field NAPL saturation. To some reviewers, estimating residual NAPL saturation in a fine-grained soil using a value such as $0.008(0.8 \%)$ may appear erroneous. However, such estimates are consistent with field measurements and observed field recovery.

What is needed is a cost effective laboratory method for better estimating residual NAPL saturation for shallow (near water table) environmental problems. Such a method needs to better simulate the field soil and spill conditions. As Kueper et al. (1993) imply, each site and spill scenario is unique and the laboratory test method will need to account for this. Future methods for determining residual NAPL saturations in environmental applications should account for the following:

- The natural structure of the soil (undisturbed soil cores should be used)

- Field moisture conditions should be simulated (do not drive samples to irreducible water saturations, unless that is justified by the likely NAPL pressure history)

- Maximum NAPL pressure should be estimated from the site specific spill history

- Maximum water pressure for imbibition should be estimated from that likely to be achieved during remedial activity

Use of testing methods that consider site-specific soil conditions of soil structure and water content, reasonable NAPL pressures resulting from the LNAPL release (maximum capillary pressure), and reasonable maximum water pressure attainable from hydraulic gradients during remediation activities, will provide more reasonable and appropriate estimates of residual NAPL saturation values. 


\section{References}

Adamski, M., Kremesec, V., Kolh atkar, R., Pearson, C., and Rowan, B., 2003, LNAPL in Fine Grained Soils: Conceptualization of Saturation, Distribution, Recovery and Their Modeling, Ground Water Monitoring and Remediation, Submitted March 2003.

API, 1998, Recommended Practices for Core Analysis, 2nd Edition, Document Number: API RP 40, American Petroleum Institute 200 pages.

Bear, J., 1972, Dynamics of Fluids in Porous Media, Elsevier Publishing, pp. 450

Bedient, P.B., Rifai, H.S., and Newell, C.J., 1994, Ground Water Contamination Transport and Remediation, Prentice-Hall, pp. 371 373.

Boley, T. M., and Overcamp, T. J., 1998, Displacement of Non-wetting Liquids From Unsaturated Sands by Water Infiltration, Ground Water, v. 36 no. 5: 810-814.

Bradley, H.B., 1987, Petroleum Engineering Handbook, ${ }^{\text {st }}$ edition, Society of Petroleum Engineers, ISBN 1-55563-010-3

Brady, N.C., 1974, The Nature and Properties of Soils, $8^{\text {th }}$ Ed., Macmillan, New York.

Brooks, R.H., and Corey, A.T., 1964, Hydraulic Properties of Porous Media, Hydrol. Pap.3., Colorado St ate University, Fort Collins.

Brost, E.J., and DeVaull, G.E., 2000, Non-Aqueous Phase Liquid (NAPL) Mobility Limits in Soil, API Soil and Groundwater Research Bulletin, June 2000, n. 9.

Charbeneau, R. J., 2003, Simple Models for Design of Free-Product Recovery Systems for Petroleum Hydrocarbon Liquids, Ground Water Monitoring and Remediation, Submitted March 2003.

Chatzis, I., and Dullien, F.A.L., 1981, Mercury Porosimetry Curves of Sandstone. Mechanisms of Mercury Penetration and Withdrawal, Powder Technology, 29 pp 117-125.

Corey, A. T., 1986, Mechanics of Immiscible Fluids in Porous Media, Water Resources Publications, ISBN-0-918334-58-6, pp 40-41

Dullien, F.A.L., 1979, Porous Media Fluid Transport and Pore Structure, Academic Press, pp 18.

Domenico, P.A., and Schwartz, F.W., 1990, Physical and Chemical Hydrogeology, Wiley \& Sons, pp. 599-600

Fetter, C.W., 1992, Contaminant Hydrogeology, Prentice-Hall, pp 225- 243.

Freeze, A.R., and McWhorter, D.B., 1997, A Framework for Assessing Risk Reduction Due to DNAPL Mass Removal from LowPermeability Soils, Ground Water, v. 35 n. 1, pp 111-123.

Hillel, D. 1982, Introduction to Soil Physics, Academic Press, Orlando.

Hoag, G.E., and Marley, M.C., 1986, Gasoline Residual Saturation in Unsaturated Uniform Aquifer Materials, Journal of Environmental Engineering, ASCE, 112(3): 586-604.

Jin, M., Butler, G.W., Jackson, R.E. Mariner, P.E., Pickens, J.F., Pope, G.A., Brown, C.L. and McKinney, D.C., 1997, Sensitivity Models and Design Protocol for Partitioning Tracer Tests In Alluvial Aquifers, Ground Water, v. 36 no. 6, pp. 964 - 972.

Kueper, B.H., Redman, D., Starr, R.C., Reitsma, S., and May, M., 1993, A Field Experiment to Study the Behavior of Tetrachloroethylene Below the Water Table: Spatial Distribution of Residual and Pooled DNAPL, Ground Water, v. 31 n. 5, pp. $756-766$.

Mercer, J.W., and Cohen, R.M., 1990, A Review of Immiscible Fluids in the Subsurface: Properties, Models, Characterization and Remediation, J. Contaminant Hydrology, v. 6, pp. 107-163

Morrow, N.R., 1987, A Review of the Effects of Initial Saturation, Pore Structure and Wettability on Oil Recovery by Waterflooding, in Proc. North Sea Oil and Gas Reservoirs Seminar, Trondheim (December 2-4, 1985), Graham and Trotman, Ltd., London, pp 179-191.

Pickell, J.J, Swanson, B.F., and Hickman, W.B., 1966, Application of Air-Mercury and Oil-Air Capillary Pressure Data in the Study of Pore Structure and Fluid Distribution, Society of Petroleum Engineers Journal, March pp 55-61

Poulsen, M.M. and Kueper, B.H., 1992, A Field Experiment to Study the Behavior of Tetrachloroethylene in Unsaturated Porous Media, Environmental Science and Technology, v. 26 n. 5, pp. 889-895, ACS.

Richards, L.A., 1950, Experimental Demonstration of the Hydraulic Criterion for Zero Water Flow in Unsaturated Soil, Trans. Int. Congr. Soil Sci. Amsterdam, 1, 67-68.

Schwille F. 1984. Migration of Organic Fluids Immiscible with Water in the Unsaturated Zone. In Pollutants in Porous Media: The Unsaturated Zone Between the Soil Surface and Ground Water, Ecological Studies, vol. 47, ed. G.D. Yaron and P. Heppie, 2748. New York: Springer-Verlag.

Schwille F. 1988, Dense Chlorinated Solvents in Porous and Fractured Media, Lewis Publishers, ISBN 0-87371-121-1

Wardlaw, N.C., and Taylor, R.P., 1976, Mercury Capillary Pressure Curves and the Interpretation of Pore Structure and Capillary Behavior in Reservoir Rocks, Bulletin of Canadian Petroleum Geology, v. 24 no.2, pp. 225-262.

Wilson, J. L., Conrad, S. H., Mason, W. R., Peplinski, W., and Hagan, E., 1990, Laboratory Investigation of residual Liquid Organics From Spills, Leaks, and the Disposal of Hazardous Wastes in Groundwater, EPA report number 600/6-90/004

Young, C. M., Jackson, R.E., Jin, M., Londergan, J.T., Mariner, P.E., Pope, G.A., Anderson, F.J., and Houk, T., 1999, Characterization of a TCE DNAPL Zone in Alluvium by Partitioning Tracers, Ground Water Monitoring and Remediation, v. XIX no. 1, winter, pp. 84-94.

Zytner, R.G., Biswas, N., and Bewtra, J. K., 1993, Retention capacity of dry soils for NAPLS, Environmental Technology, v. 14: 1073-1080. 


\section{Biographical Sketches}

\section{Mark Adamski, P.G.}

Mark is an Environmental Business and Technology Manager with GEM a BP affiliated company. He has spent his 10 year Amoco/BP/GEM career remediating hydrocarbon contaminated sites as well as modeling fluid flow for both environmental and petroleum exploration projects. His environmental experience has been focused on chemical and refining facilities. He has a BS in Geological Engineering from the University of Arizona and a M.S. in Hydrogeology from Texas A\&M University.

\section{Dr. Victor Kremesec, PhD}

Vic Kremesec has over 12 yr experience remediating hydrocarbon contaminated sites for GEM a BP affiliated company. He is a member of the Advisory Committee for the API Soils/Groundwater Technical Task Force and a member of the Technical Advisory Committee of the Florida DEP. He has a Ph.D. in Chemical Engineering from Northwestern University.

\section{Dr. Randall Charbeneau, PhD}

Randall Charbeneau is a professor at The University of Texas at Austin (Department of Civil Engineering, University of Texas, Austin, TX 78712), where he has served on the faculty since 1978. During this period he has been involved with many research projects dealing with migration and fate of hazardous and radioactive materials, ground water modeling, and subsurface remediation. 